\title{
REVIEW
}

\section{THE SOCIAL REPORT (TÁRSADALMI RIPORT) 2018 AND THE HUNGARIAN SOCIAL REPORT 2019}

\author{
RÉKA KEMÉNY $Y^{2}$
}

The Hungarian Social Report series has been published every second year since the first free elections after the collapse of the communist regime (1990) with the aim of documenting and interpreting changes in Hungarian society, always based on the most current and systematically collected data. In the fifteenth volume, entitled Social Report 2018, editors Tamás Kolosi and István György Tóth express their wish to always reflect on the important changes in Hungarian society, for which reason, from time to time, they modify the questions that are examined and the approach in subsequent volumes. The series is built upon research undertaken by the leading Hungarian think tank TÁRKI Social Research Institute, but due to editorial intentions it usually contains various analyses from other studies from the Hungarian social research scene (in the current volume, a maximum of one half of the chapters, authors, and research belong to TÁRKI). The Social Report 2018 has five main blocks, which, in order, focus on the structure of society and its more important indices; an analysis of socio-demographic groups and their situation; the economy; indicators of the success of social policies; and last but not least, values and attitudes - in a total of 22 chapters. At the end of the volume, each author is briefly introduced; furthermore, some recollection of individual chapters from the earlier 15 volumes is presented.

In early 2019 the English edition, the Hungarian Social Report 2019, was also published. It is the fourth English volume, the last being published in 2004, which is also the year Hungary joined the EU. Besides the year of publishing, not only does the appearance of the English volume differ from the Hungarian one (having a different size and color), but it also contains 19 chapters, out of

1 The first is edited by Tamás Kolosi and István György Tóth; the latter by István György Tóth (Budapest, TÁRKI Social Research Institute, 2018, 2019)

2 Réka Kemény is a Ph.D. student at the Corvinus University of Budapest, e-mail: reka.kemeny@ uni-corvinus.hu 
which 12 chapters are exact translations of those in the Hungarian edition, while 7 chapters are new. The structure of the chapters is also different from that of the Hungarian volume (e.g. the block on the economy has disappeared completely), and although the authors of the English edition are also introduced at the end of the book, there is no recollection of the individual chapters in previous (English) volumes.

In my review, I first introduce the content of the Hungarian edition, and then briefly focus on the new chapters and the differences in the English edition. My main goal is to provide general insights into the Hungarian volume, therefore I introduce each chapter; however, due to considerations of length, the latter descriptions are shorter than they deserve to be.

\section{Social Structure}

The first block opens with a study by one of the editors, Tamás Kolosi, and his colleague Péter Szívós, entitled “Is Europe far away?" In this chapter the authors study through the concept of $\beta$-convergence whether the old wish of Hungarian society since the change of regime - to catch up with the European economy and living conditions - has happened, and whether specific hypotheses may be confirmed. The researchers compare Hungarian data to the average of the most developed EU-15 countries, as well as four reference countries: developed Austria, Portugal - the least developed Western European country -, and postcommunist Poland and Romania. They analyze such "catching up" through a complex approach that involves multiple indicators and find that although Hungary has moved closer to the EU-15, this movement has been slower than in the case of the other two ex-communist countries. The next three chapters are built around the concept of social mobility, while the second study focuses on the closure and fluidity of Hungarian society, as written by co-editor István György Tóth, and Iván Szelényi. Based on international, primarily American, literature, the authors state that fractures in society exist not only between the upper 1 and 99 percent, but the borders are becoming more rigid between the uppermiddle class and other strata of society. For this reason, their primary question is whether increasing inequality and decreasing mobility can be detected in the upper $10 \%$ and the remaining $90 \%$ of Hungarian society. Based on American literature and Hungarian intergenerational income data, the researchers come to the conclusion that although Hungarian society is less unequal than American society, inequality has increased since the regime change. They also find that, despite the low level of inequality, the degree of intergenerational mobility is low, a finding which contradicts the hypothesis of the so-called Great Gatsby Curve. 
Researchers Zoltán Kmetty and Júlia Koltai examine social mobility using a network approach. In their study it is outlined how intergenerational mobility has been associated with network resources in the past 20 years in Hungary. The authors state that the direction of causality is not clear in this research situation: networks can increase mobility, but mobility itself can influence the number and quality of connections. The study is based on three periods of data collection, each carried out using a position generator method. The researchers created two indexes to measure nexus diversity and high-status occupations, and contrasted these with educational and occupational mobility, and the supply of material resources of the interviewees. They find, inter alia, that from the perspective of a network approach those who are in a bad situation have parents whose status was also low, and they themselves have not been able to escape their situation. In their research, Kmetty and Koltai study not only "good" connections but also "bad" ones and find that while positive connections signal higher status, negative ones signal a lower one. The last chapter, with a focus on social mobility, was written by Péter Róbert who studies intergenerational educational mobility in European countries before and after the global economic crisis at the end of the early 2000s. The aim of the study was to describe and explore the differences between countries from the perspective of educational mobility by analyzing the first seven waves (2002-2014) of the European Social Survey (hereinafter, ESS) in those 16 countries which took part in all waves to assess whether the effect of social origin (the educational attainments of parents) on educational attainment increased or decreased after the crisis. The researcher finds that educational mobility is very low in Hungary, and social origin has a huge effect on the opportunity to obtain a degree in higher education. Another finding of the study is the lack of clustering of countries which typically move together (e.g. Scandinavian countries), although the "qualification surplus" related to an advantageous parental background is found to be higher among the post-communist and Southern European countries. Ágnes Hárs also focuses on mobility, but, differing from the previous studies, approaches the topic from an international context: she scrutinizes the increase in outward migration. The aim of the study is to assess where Hungary is located in the process of the increasing emigration of the Eastern European region, and what the characteristics and the expected effects are for the Hungarian labor market. Based on the EU-Labour Force Survey (hereinafter, EU-LFS) the author states that since the enlargement of the EU in 2004 growth in emigration has been persistent, although Hungary is one of those countries in which the level is moderate. The author contrasts data by educational attainment and age and finds that the "brain drain" is greatest in Hungary, since it is away from this country that most people that obtain a degree migrate. The author also addresses how many people have left and returned 
from the three most popular recipient countries (Austria, Germany, and the UK) in recent years, and examines what the characteristics are of this population. At the end of her study, Hárs analyses the factors affecting immigration regarding Hungary, and possible return to the country.

\section{Demographic Groups}

The second block opens with a chapter about the connections between household structure and educational attainment, written by Judit Monostori and István Harcsa. The authors analyze data from the three censuses since 1990 and the microcensus in 2016 to identify what the patterns of household structure were during the different stages of the life course, and what the connection of these is with educational attainment. The authors treat youth, having children, and parental status, as highlighted stages. They find that an increasingly large proportion of youth (aged 18-39) live "as children" in the parental household; that leaving the parental home is no longer a one-off, final act, and that this form of co-habitation is greater among people with lower educational attainment. They state that, concerning educational attainment, a realignment has occurred within the group of single mothers, and that after 1990 the proportion of those having children dropped dramatically, and they call attention to the fact that there is very little data about mosaic families. Further main results are that due to the realignment of society according to age, the proportion of households that consist of elderly persons has increased, and the share of households with three or more generations has decreased. Réka Branyiczky and András Gábos study the dynamics of poverty during the economic crisis using the longitudinal database of EU-Statistics on Income and Living Conditions (hereinafter, EUSILC). In their analysis they find that in European comparison the proportion of cross-sectional and persistent income poverty is low, but both cross-sectional and persistent extreme material deprivation are exceptionally high. The authors observe the dynamics of income poverty and extreme material deprivation and come to the conclusion that the latter is associated with a more powerful, greater out- and inflow rate within certain categories, while members of this group have a better social background than those of the former group. Finally, a multivariate statistical analysis seems to confirm the assumption that it primarily the situation of groups with a better status (lower-middle class, middle class) that improved with the easing of the economic crisis; i.e. of those who only temporarily found themselves in a tough situation during the economic and financial crisis. Anikó Bernát studied the social integration of the Hungarian Roma in the 2010s. In her research, she investigates whether positive economic 
and social processes have reached one of the traditionally most disadvantaged groups in Hungarian society, the Roma. The data are based on a monitoring study that had Bernát as a co-author, and databases from the Hungarian Central Statistical Office (hereinafter, HCSO) which include questions on nationality and ethnicity such as those in the EU-LFS and the EU-SILC. All in all, the author finds that the boom has partly reached the Hungarian Roma, and their situation has become better, primarily in terms of employment - but regarding their income, much less so. An important source of the growth in employment is public work, which also accounts for the only weak improvement in income. Furthermore, the author highlights that the situation of the Hungarian Roma within Southern and Eastern Europe can be defined as one of the best. Nevertheless, she calls attention to indices of education which still signal a huge gap between Roma and non-Roma youth in Hungary. Borbála Simonovits and Blanka Szeitl analyze the situation of women and men in Hungary in international comparison. The study is built upon multiple databases, including those of the HCSO, OECD, Eurostat, European Institute for Gender Equality (EIGE), the Global Gender Gap Report etc., but the researchers have also incorporated relatively "unusual" sources such as the Hungarian edition of the magazine ELLE. The authors study temporal trends in the field of the labor force, education, and political and cultural life. In representing the trends in the field of the labor market, they stress that the introduction of new types of childcare leave and benefits in 2014 and a program named "Women 40" (which in a discriminatory way allows only women to retire earlier than the statutory age) have had the most influential effect on this group. The authors state that the elimination of the gender pay gap in Hungary may be expected in around 2102, and that a sharp difference currently exists within the sectors in this regard. As for political representation, the authors note that the second government of Gyurcsány (2006-2009) and the current, fourth government of Orbán (in 2018) contained the highest proportion of women. In the last chapter of the block Márton Medgyesi analyses the income and labor market situation of youth in the period since the start of the economic crisis in 2008 in EU countries. Based on literature and data from the EU-LFS he states that the unemployment rate of youth is always higher on average than the total unemployment rate, but the crisis has deepened the difference: the unemployment rate increased more among youth, and the NEET-rate (Not in Education, Employment or Training) also rose during the crisis. Furthermore, forms of atypical employment such as fixed-term contracts and part-time jobs have become more widespread, too. The author finds that, since 2014, the youth unemployment rate has decreased in most EU member states to a greater extent than the total unemployment rate, and, in parallel with this, that the increase in the poverty rate between 2010 and 2014 has ceased in most countries too. 
The author also reveals that the consequences of the economic crisis were more severe among young adults from low-status families, and shows that the family background of youth served to protect against unemployment in wealthier families, and that the children of these families were also more likely to count on assistance from their families when unemployed.

\section{Economy}

Éva Palócz and Péter Vakhal study the formation of the stratum of mediumsized companies from 2000-2016 in the frame of an extended case-study. Based on literature and a database of Structural Business Statistics, the authors point out there is a correlation between companies of a larger size and a higher level of production; it is for this reason they found it important to examine whether there has been a change in company size in Hungary since the millennium. The researchers studied what kind of changes happened between 2000 and 2016 in medium-sized companies with 50-249 employees which were operating in 2000 through an analysis of the databases of the National Tax and Customs Administration of Hungary. The result is that out of the 3350 enterprises in 2000, 1800 companies had ceased business, 600 had shrunk to become small-sized ones, and 300 to micro-sized businesses. Only 600 companies had remained medium-sized, and only half of these had increased their headcount. From the starting population, only 50 businesses had managed to become big enterprises. The same authors investigated Hungarian competitiveness according to objective and subjective indices. First, they present objective indices such as Unit Labour Cost, Real-Exchange Rate, and Revealed Comparative Advantage. They then turn to the competitiveness index of the World Economic Forum (WEF) which gives a much broader overview of the subject of research. Seventy percent of this index is subjective, based on the Executive Opinion Survey, while 30\% is constituted of objective indices. Through applying the WEF-index Palócz and Vakhal analyze the competitiveness of Hungary and the three other Visegrad Four countries, plus Austria and Romania in the last decade. They find that among the countries under scrutiny the subjective indices worsened in each case except for in Poland, while executives judge the Hungarian economic situation to be the worst. Attila Wieszt and György Drótos conducted a survey between September 2017 and February 2018 among the total population of Hungarian family-owned businesses to explore their general statistical patterns, internal distribution, and internal working mechanisms and to obtain a wider picture of them. In the analysis, the authors point out that family-owned businesses make up the majority of the economic entities in Hungary, but as for the size of the 
enterprises, the proportion constantly decreases from small-sized companies to big ones. The researchers also demonstrate that family-owned businesses are capable of developing from micro-sized ones into strong, small-sized enterprises in the case that the founder(s) constantly incorporate more family members into their operations. However, these businesses are less likely to become medium-sized companies from small-sized ones by involving external expertise into management besides/instead of family members. Imre Kovách's study is entitled "Land-use and Land-ownership." The author introduces the historically and internationally significant concentration of land-use in postregime-change Hungary based on databases from the HCSO and the Single Area Payment Scheme of the EU. Kovách points out that land ownership in Hungary now typically involves areas of a significant size which have partly been created using EU resources. According to his assessment, the concentration of land-use and land ownership is the result of poor settlement and enforcement of the land compensation law, a rapid and radical reduction of agricultural support, and also serial political interventions. Furthermore, the author calls attention to the fact that, in parallel to the increasing concentration, the number of land users has dropped dramatically, with up to a million individuals having stopped farming by 2016, which may be one cause of the rural poverty in Hungary.

\section{Human Infrastructure}

Judit Lannert's study is about Hungarian education and the challenges of the twenty-first century. Based on thus far available data, the education researcher analyses why Hungarian pupils constantly underperform in maths and digital literacy and explains why family background is still the most influential factor in the educational results of children in Hungary. The author shows that talent fostering does not work in Hungary either, while the proportion of those who underperform in all three fields of the PISA measures is growing, and the school system is selective. Based on the results of a national competence study, Lannert analyses the effect of pedagogical assessment on pupils' performance, and from analyzing education-related public opinion surveys finds that not only has the motivation of learners dropped in the last couple of years, but the adult population has no motivation for learning either. Gabriella Lantos examines the development of the Hungarian private health sector. The author explains that although private healthcare existed during communist times, at that time it was still a luxury, while during the last ten years it became a part of everyday life and a system at the same time. Lantos introduces private service providers and also the characteristics of those who pay for the services of private healthcare 
and their underlying motivations. There is little data at the author's disposal, but from analyzing it she comes to the conclusion that demand for private healthcare has been continuous for years and will not decrease due to the lack of reform in the public sector. The fact that doctors and medical staff have shifted to the private health sector and have not migrated abroad (but stayed within the borders of Hungary) is evaluated positively by Lantos, since in her interpretation this is a sign that private healthcare represents a true alternative. József Hegedüs, Eszter Somogyi and Nóra Teller study the housing market and housing indicators. They describe the trends in the housing market and the regime of housing policies after the millennium, the boom in the housing market in 20002008, the long-continuing effects of the economic crisis until 2014, and the signs of a revival in the housing market after 2015. Based on the Housing Survey of the HCSO in 2003 and 2015, the authors introduce the position of certain social groups in the housing market. Finally, the researchers analyze why the current housing market situation is similar to that of the period 2000-2008 with a presentation of the differences (e.g. forms of housing support now and then). Marianna Kopasz and András Gábos are the first to put under scrutiny how the support-related behavior of local governments changed after the modification of the Social Law of 1993 (which came into force in March 2015), since the modification granted greater decision-making authority to local governments regarding both the number of people who receive aid and the related expenses. Short-term effects were studied for the year before the modification, the year of the modification, and the subsequent year. The authors find that between 2014 and 2016 the number of people who received any form of the aid under study did not change essentially, but significant realignment happened among the aid objectives: fewer people received housing aid (which was earlier based on normative principles), but the proportion of people receiving "other" forms of aid increased significantly.

\section{Attitudes}

Gábor Tóka analyses Hungarian parliamentary elections in 2018, stating that it is a unique phenomenon in a democracy for one party to win two-thirds of all mandates for a third time. After a short overview of election results, Tóka analyses in a detailed way the unexpectedly high (the highest among Hungarians living within the territory of the state since 1990) turnout and the potential cause of this. After this, the author explains party popularity after 2014 by claiming that making the refugee crisis after 2015 a topic of public policy led to new votes for the governing party. However, Tóka points out that one explanatory 
variables of party sympathy is the index of consumer confidence, and it is visible that the former index of the Hungarian population in 2014-2018 was uniquely high and increased between 2016 and 2018. Social psychologist Péter Krekó studied the "image of Russia" in Hungarian public opinion. He argues that, in spite of the historical view which claims that in matters of public opinion surveys public opinion is formed by historical experience, public opinion can be shaped by political impulse without restraint. The research is based upon a large sample survey which the author uses to review the changes that have happened in Hungarian public opinion regarding Russia and its leader in the last couple of years - and puts the outcomes into international context. Krekó points out that despite the characterization of Hungary as having a Westernfriendly attitude, which is especially high in regional comparison, and despite the fact that the majority of the Hungarian population imagine the country's role as a bridge between the East and the West, a Russia-friendly attitude has been constantly strengthening since the regime change, and was highest during the third government of Viktor Orbán (2014-2018). András Jakab and György Gajduschek analyze the situation of the rule of law, legal awareness, and the following of legal norms. They find that the state of the rule of law has been in constant decline in Hungary for a couple of years, following a downward trend. To demonstrate this, the authors use various rule-of-law indexes which focus on legal practice (e.g. how many days it takes to accept a new law), not on an analysis of formal laws. They analyze legal awareness with the help of the World Value Survey and the ESS and find that the feeling in Hungary that breaches of the law remain unpunished has become general; moreover, that to become successful one has to break the law. Furthermore, the authors analyze through the application of different indices to what extent legal norms are adhered to. Márton Medgyesi and Zsolt Boda's study is entitled "Trust in institutions in Hungary and in the countries of the European Union." The authors study changes in institutional trust based on data from the Eurobarometer (2007-2016) and the Quality of Life Survey (2007-2016). Their most important finding is that institutional trust has increased in most European countries in the last couple of years, and the level is higher than prior to the economic crisis. They also find that while in most countries the level of trust decreased during the crisis (20072011), there was no decrease in the case of Hungary since the recession started earlier here, in 2006, and thus the level of trust also fell earlier.

As mentioned earlier, the English edition varies from the Hungarian one in terms of structure and number of chapters, too. From the 22 chapters of the 2018 volume, 12 have been incorporated into the English edition. The seven new chapters include an analysis by Zsolt Spéder, director of the Hungarian Demographic Research Institute, on trends in fertility, mortality, and age 
distribution and ageing in Hungary after the regime change. Réka Branyiczki and András Gábos have a second chapter in the English volume, together with Péter Szívós, in which they assess the level of poverty and social exclusion in Hungary and the EU over the past 10-15 years based on the EU-SILC database. The main difference compared to their other study is that this new one analyses cross-sectional data, while the other one focuses on the dynamics of poverty using longitudinal data. The editor of the volume, Tamás Kolosi, and his colleague Krisztián Pósch analyse Hungarian society's social class structure and social stratification together with society's self image from the early 2000 s until 2012. Judit Lannert's study of the Hungarian education system is not part of the English edition, but instead a chapter by Benő Csapó et al. has been included. This reviews changes in educational outcomes since 1970 and compares them with results from other countries. Furthermore, the authors shed light on the relationship between educational results and family background and social inequalities. Likewise, Gabriella Lantos' study of the development of the public health sector has been removed, and a chapter by Éva Orosz and Zsófia Kollányi that includes an assessment of Hungary's position in terms of health status and health inequalities in the European context, and between different social groups within the country, has been added. Bori Simonvits and Blanka Szeitl wrote about the attitudes of Hungarian and European citizens towards asylum seekers before, during, and after the peak of the migration crisis that affected Europe in around 2015. István György Tóth and Iván Szelényi’s analysis of social closure and fluidity has been enriched with new parts in the English edition. The only question which is left unanswered by the editor of the English volume is why it consists of different chapters, and why an exact translation of the Hungarian edition was not provided for an international audience. It would have been interesting to read about what the selection criteria were for the studies in the 2018 volume, and moreover, why new ones were included in the 2019 volume.

In my opinion, the strength of the volumes is that besides the interpretation and evaluation of various surveys and data sources (which is the defined goal of the Social Reports), the studies include a variety of figures and tables which help readers to understand the phenomena concerned. However, the figures are hard to read sometimes - perhaps bigger, color versions could solve this problem in the next edition. Furthermore, the editors have made a fantastic job of referring in one chapter to others when the topics or findings are related: e.g. in the chapter on the closure and fluidity of Hungarian society in the Hungarian edition the results of the analysis on educational mobility are noted.

As the editor puts it in the English edition, "the readership of the Hungarian Social Reports is very wide," which proves to be true of the Social Report 2018 and the Hungarian Social Report 2019 as well, in part due to the clear, 
interpretative language of the authors. The series represents a good start for anyone (social scientists, policy makers, as well as laymen) who wishes to understand contemporary Hungarian society. 
